\title{
The Search for Units of Meaning: The Case of Collocational Framework "the * of"*
}

\author{
YANG Su-xiang \\ Henan Polytechnic University, Jiaozuo, China
}

\begin{abstract}
The concept of collocational framework has been put forward by Renouf and Sinclair in 1991, but few researchers have investigated on the construction of the units of meaning based on collocational framework. This study searched for the units of meaning of collocational framework "the * of" employing Sinclair's lexical grammar model. The results show that collocational framework "the * of" has its own lexical grammar features and can construct its units of meaning. The units of meaning form "Existences/Activities + the + Activities/Essences + of + Social Lives/Persons" sequence and express the "exist the activities or essences of social life and person" or "act the activities or essences of social life and person".
\end{abstract}

Keywords: units of meaning, collocational framework, general written English

\section{Introduction}

Sinclair, the forerunner of Corpus linguistics, claims lexical items as "units of meaning" (Sinclair 1996/2004) or "extended units of meaning" (Sinclair, 2007) and provides a model of the construction of meaning. Sinclair's model is composed of five categories of co-selection, namely "the core", "semantic prosody", "semantic preference", "collocation", and "colligation". The lexical item is taken to "realize an element of meaning which is the function of the item in its cotext and context" (Sinclair, 2004, p. 121).

It is relatively recently that an increasing number of studies have attempted to explore the extent of phraseology or to analyze the inner workings of the phraseological tendency in the English language. These include the studies of units of meaning (Sinclair, 1987, 1996, 2004, 2007); pattern grammar (Hunston \& Francis, 2000), lexical bundles (Biber \& Conrad, 1999; Biber et al., 1999; Biber, Conrad, \& Cortes, 2004), n-grams (Stubbs, 2007), chains (Stubbs, 2002), recurrent word combinations (Altenberg, 1998), etc.

Most of the above researches are based on continuous word combinations or phrases. Some scholars such as Renouf and Sinclair (1991), Marco (2000), Eeg-Olofsson and Altenberg (1994) explored the discontinuous collocational frameworks in the past decade. Collocational frameworks is "a discontinuous sequence of two words, positioned at one word remove from each other; they are therefore not grammatically self standing; their

\footnotetext{
* Acknowledgements: This paper is supported by (1) the Fund of the Doctoral Scientific Research in Henan Polytechnic University (No. SZB2013-39) on "The Constructional Mechanism of Units of Meaning in Terms of Corpus linguistics and (2) the Fund of Key Project of Science and Technology of Henan Office of Education (14B880017) on "The Creation and Application of the English and Chinese Bilingual Parallel Corpora on Tai Chi”.

YANG Su-xiang, associate professor, Ph.D., supervisor of M.A. students, School of Foreign Studies, Henan Polytechnic University.
} 
well formedness is dependent on what intervenes" (Renouf \& Sinclair, 1991, p. 128). However, considering that discontinuous word combinations or phrases are important integrating parts of phraseology; hence it needs further and deep researches.

Therefore, in the present study, the units of meaning based on collocational framework, a discontinuous structure, will be investigated in order to explore the construction of units of meaning. Therefore, the research questions are: (1) What are the lexical grammar profiles of units of meaning based on collocational framework? (2) How does collocational framework construct units of meaning?

\section{Research Design}

\section{Corpus Used}

In this study, the search of units of meaning will be conducted in general written English, the BNC-Written, which comprises the written part of the British National Corpus. The BNC is a balanced synchronic text corpus containing 100 million words, about 90 percent written and 10 percent spoken texts. The written part includes Applied Science, Arts, Belief and Thought, Commerce and Finance, Imaginative, Leisure, Natural and Pure Science, Social Science, and World Affairs.

In this study, the BNC-Written is used to extract middle, left, and right collocates of "the * of" in order to find the meaning construction of the units of meaning based on the collocational framework "the * of", and to generalize typical patterns of units of meaning based on collcational framework.

\section{Tool Used}

The tool used in this study is WordSmith Tools 5.0. In this study, we use WordSmith 5.0 to extract Left 1, Middle, Right 1 collocates of collocational framework "the * of" in order to find the words exactly before, in the middle and after "the * of".

\section{Research Methods}

In this study, the analytical unit is a five-word string " $\mathrm{L} 1 \mathrm{C}+$ the $+\mathrm{MidC}+$ of $+\mathrm{R} 1 \mathrm{C}$ " based on "the * of". L1C stands for Left 1 collocate, MidC means Middle collocate, and R1C is Right 1 collocate. The first step is to use "the * of" as the core and retrieve collocates, and then manually weep out the lines broken by punctuation between the five-word strings. The second step is to analyze the collocation, parts of speech, semantic categories, etc. The third step is to discuss the construction of the units of meaning. It needs to point out that there are so many tokens and types to handle in each position, therefore, the collocates considered in this study are based on the top 300 types in Left 1, Middle and Right 1 position. What is more, due to the limitation of the space, the detailed description and the tables of the parts of speech of the collocates are omitted in this paper. For more data, please contact the author.

\section{Research Results}

In this section, the lexical grammar profiles of Middle, Left 1, Right 1 collocates of the collocational framework are displayed in terms of collocation and semantic categories.

\section{Middle Collocates}

The extracting results of the Middle collocates are 897,628 tokens and 8,390 types. This part shows the 
results of the collocation and semantic categories of Middles collocates.

(1) Collocation.

Table 1 shows the ranking orders, raw frequencies, normalized frequencies of the top 30 Middle collocates in the BNC-Written. In Table 1, R, MidC, RF, and NF stand for Ranking, Middle collocates, Raw frequencies, and Normalized frequencies correspondingly. Words in bold belong to the first top categories in semantic category, and words in shadow are in the second top semantic category, words underlined to the third top semantic category. The subsequent tables will follow the same format.

Table 1

Top 30 MidC in the BNC-Written

\begin{tabular}{|c|c|c|c|c|c|c|c|}
\hline $\mathrm{R}$ & MidC & $\mathrm{RF}$ & NF & $\mathrm{R}$ & MidC & $\mathrm{RF}$ & NF \\
\hline 1 & end & 18,966 & 210.73 & 16 & secretary & 3,836 & 42.62 \\
\hline 2 & number & 9,188 & 102.09 & 17 & top & 3,831 & 42.57 \\
\hline 3 & use & 8,889 & 98.77 & 18 & role & 3,711 & 41.23 \\
\hline 4 & rest & 7,761 & 86.23 & 19 & age & 3,603 & 40.03 \\
\hline 5 & development & 5,858 & 65.09 & 20 & effect & 3,564 & 39.6 \\
\hline 6 & case & 5,443 & 60.48 & 21 & importance & 3,512 & 39.02 \\
\hline 7 & nature & 4,622 & 51.36 & 22 & middle & 3,501 & 38.9 \\
\hline 8 & time & 4,414 & 49.04 & 23 & centre & 3,478 & 38.64 \\
\hline 9 & basis & 4,280 & 47.56 & 24 & work & 3,450 & 38.33 \\
\hline 10 & form & 4,223 & 46.92 & 25 & presence & 3,384 & 37.6 \\
\hline 11 & idea & 4,027 & 44.74 & 26 & value & 3,384 & 37.6 \\
\hline 12 & house & 4,007 & 44.52 & 27 & $\underline{\text { amount }}$ & 3,305 & 36.72 \\
\hline 13 & back & 4,006 & 44.51 & 28 & level & 3,285 & 36.5 \\
\hline 14 & $\operatorname{cost}$ & 3,913 & 43.48 & 29 & possibility & 3,121 & 34.68 \\
\hline 15 & beginning & 3,869 & 42.99 & 30 & course & 3,060 & 34 \\
\hline
\end{tabular}

(2) Semantic categories.

The semantic categories of Middle collocates are Person, Activity, Quality, Quantity, Time, Space, Essence, Social life, natural phenomenon. However, the top three categories of the Middle collocates in the BNC-Written are: Activitys (use, development, cost, effect, work) (see Table 1 the words in bold); Essence (case, nature, basis, idea, role) (see Table 1 the shadowed words); Quantities (number, amount, level, possibility, majority) (see Table 1 the underlined words). The semantic categories, frequencies, and percentage of Middle collocate are as follows:

Table 2

Semantic Categories, Frequencies, and Percentage of MidC

\begin{tabular}{lll}
\hline Semantic category & NF & $\%$ \\
\hline Activities & 1482 & 28.33 \\
Essence & 1467 & 28.04 \\
Quantities & 687 & 13.13 \\
\hline
\end{tabular}

Table 2 shows that Middle collocates chiefly express the meaning of Activities, Essence, Quantities, etc. Activities (28.33\%) are usually the nominalization of verbs. Nominalization here refers to the conversion of processes into nominals or verbs into nouns, which indicate movement from spoken language to written language or from the congruence to metaphorical form (Halliday \& Matthiessen, 2004). Nominalization is the single most 
powerful resource for creating grammatical metaphors. By this device, processes (congruently worded as verbs) and properties (congruently worded as adjectives) are rewarded metaphorically as nouns; instead of functioning in the clause as Process or Attribute, they function as Thing in the nominal group (Halliday \& Matthiessen, 2004). It also illustrates that when people write something, they usually use nominalization, which makes their opinion more objectivity avoiding subjectivity, especially in academic writing.

Category Essence (28.04\%) demonstrates that Middle collocates usually focus on the nature or concept of the things, which express the abstract features of persons, things, and events. The reason for that may be simply as Halliday and Matthiessen (2004) and Halliday (2009) claim when it is more formal and technical, the language becomes more abstract. Essence stated above is usually made up of abstract nouns. Furthermore, the BNC-Written comprises written texts and a large number of the texts are academic texts, which are comparatively formal and technical, hence a large amount of words expressing abstract concepts are dropped into the middle of collocational framework "the * of".

Category Quantities (13.13\%) display that the words in the middle of collocational framework in general written English usually express the quantity of the words which follow the framework "the * of", just like the structure of "a * of", in which many words in the middle positions are quantitative words, such as "a lot of", "a number of", "a couple of", etc. (Renouf \& Sinclair, 1991). The tentative explanation is that quantities before "of" is one of the usages of the preposition "of".

In summary, the Middle collocates primarily express the meanings of Activities, Essence and Quantities through the methods of nominalization, abstraction, and quantification.

\section{Left 1 Collocates}

For Left 1 collocates, the total type is 6,149 times and the total token is 804,263 times. The top 300 types indicate a very typical patterns, on which the units of meaning based on collocational framework are constructed. This part shows the results of the collocation and semantic categories of Left 1 collocates.

(1) Collocation.

The top 30 Left 1 collocates in the BNC-Written are shown in Table 3.

Table 3

Top 30 L1C in the BNC-Written

\begin{tabular}{|c|c|c|c|c|c|c|c|}
\hline $\mathrm{R}$ & $\mathrm{L} 1 \mathrm{C}$ & RF & $\mathrm{NF}$ & $\mathrm{R}$ & $\mathrm{L} 1 \mathrm{C}$ & $\mathrm{RF}$ & $\mathrm{NF}$ \\
\hline 1 & in & 84,950 & 943.89 & 16 & into & 6,514 & 72.38 \\
\hline 2 & of & 53,954 & 599.49 & 17 & under & 5,222 & 58.02 \\
\hline 3 & to & 49,645 & 551.61 & 18 & over & 4,948 & 54.98 \\
\hline 4 & at & 39,131 & 434.79 & 19 & through & 4,500 & 50 \\
\hline 5 & on & 39,019 & 433.54 & 20 & $\underline{\text { but }}$ & 4,496 & 49.96 \\
\hline 6 & and & 33,142 & 368.24 & 21 & be & 3,827 & 42.52 \\
\hline 7 & for & 30,737 & 341.52 & 22 & after & 3,800 & 42.22 \\
\hline 8 & with & 26,306 & 292.29 & 23 & between & 3,092 & 34.36 \\
\hline 9 & by & 24,646 & 273.84 & 24 & all & 3,067 & 34.08 \\
\hline 10 & that & 17,838 & 198.2 & 25 & within & 3,045 & 33.83 \\
\hline 11 & from & 17,328 & 192.53 & 26 & or & 3,020 & 33.56 \\
\hline 12 & is & 13,632 & 151.47 & 27 & against & 2,882 & 32.02 \\
\hline 13 & as & 9,891 & 109.9 & 28 & are & 2,641 & 29.34 \\
\hline
\end{tabular}




\begin{tabular}{llllllll}
\hline 14 & was & 8,726 & 96.96 & 29 & before & 2,579 & 28.66 \\
15 & about & 8,689 & 96.54 & 30 & since & 2,517 & 27.97 \\
\hline
\end{tabular}

Notes. The meanings of the marker are like Table 1.

Table 3 illustrates the top 30 Left 1 collocates, which show that most of the top 30 collocates are prepositions, verbs, and conjunctions, which is in line with our prediction that there are extreme prepositions in Left 1 position. As we look down the top 300 Left 1 collocates (As a result of limitations of space, it is not listed in the present paper), we find that following the high frequency collocates are adverbs, nouns, and so forth, but they are not in the top 30 Left 1 collocates in Table 3.

(2) Semantic categories.

It needs to point out that only the lexical words are considered in semantic classification. The top three most frequent semantic categories are Existence verbs (is, was, be, are, has); Activity verbs (take, make, meet, reached, prevent); Mental verbs (see, saw, consider, understand, know). It should be noted that the names of the categories are consisting of two parts, first part is the meaning of the categories, the second part is the parts of speech. The frequencies and percentage of the above semantic categories are listed as Table 4.

Table 4

Semantic Categories, Frequencies, and Percentage of L1C

\begin{tabular}{lll}
\hline Semantic category & NF & $\%$ \\
\hline Existence verbs & 479 & 37.78 \\
Activity verbs & 251 & 19.79 \\
Mental verbs & 152 & 11.99 \\
\hline
\end{tabular}

Table 4 shows that Existence (37.78\%), Activity (29.79\%), and Mental verbs (11.99\%) are the most frequent semantic categories in terms of frequency, which may be the characteristics of written texts. Biber et al.'s (1999, p. 366) results illustrate that in fiction, news, and academic prose, the rank of the frequency of verbs are activity verbs, existence verbs, and mental verbs. From fiction to academic, the existence verbs increase and activity verbs decrease respectively. "(I)n academic prose, existence verbs are almost as common as activity verbs" (ibid., p. 366). In fact, this study shows that Existence verbs in written text are much higher than Activity verbs. This phenomenon could be explained that the written texts in the BNC are more academic and formal. In addition, the third highest category in the present study is Mental verbs, which is similar to that in Biber et al.'s (1999) results.

\section{Right 1 Collocates}

In this section, the collocation and semantic categories of Right 1 collocates in the BNC-Written will be explored, and the aim of it is to find the lexical grammar profiles of Right 1 collocates. For Right 1 collocates, the total types are 11,374 times and the total tokens are 835,891 times, and the top 300 types are investigated.

(1) Collocation.

This part discuss collocates in Right 1 position, the data of collocates in Right 1 position are shown in Table 5 . 
Table 5

Top 30 R1C in the BNC-Written

\begin{tabular}{llllllll}
\hline $\mathrm{R}$ & R1C & RF & NF & R & R1C & RF & NF \\
\hline 1 & the & 246,146 & 2734.96 & 16 & it & 3,182 & 35.36 \\
2 & a & 53,657 & 596.19 & 17 & my & 3,070 & 34.11 \\
3 & his & 16,193 & 179.92 & 18 & one & 3,061 & 34.01 \\
4 & this & 11,602 & 128.91 & 19 & your & 3,047 & 33.86 \\
5 & an & 9,730 & 108.11 & 20 & those & 2,895 & 32.17 \\
6 & their & 9,259 & 102.88 & 21 & England & 2,769 & 30.77 \\
7 & her & 7,391 & 82.12 & 22 & some & 2,477 & 27.52 \\
8 & its & 5,028 & 55.87 & 23 & which & 2,440 & 27.11 \\
9 & these & 4,904 & 54.49 & 24 & new & 2,177 & 24.19 \\
10 & state & 4,519 & 50.21 & 25 & being & 2,168 & 24.09 \\
11 & all & 3,981 & 44.23 & 26 & what & 2,135 & 23.72 \\
12 & our & 3,834 & 42.6 & 27 & each & 2,032 & 22.58 \\
13 & such & 3,300 & 36.67 & 28 & two & 1,949 & 21.66 \\
14 & that & 3,282 & 36.47 & 29 & life & 1,843 & 20.48 \\
15 & any & 3,247 & 36.08 & 30 & people & 1,722 & 19.13 \\
\hline
\end{tabular}

Table 5 shows that Right 1 collocates are most modifiers or nouns. The detail will be discussed in the following semantic categories.

(2) Semantic categories.

The semantic categories in Right 1 position are divided into different categories in light of Nouns, Adjectives, Verbs, and Adverbs. The top three semantic categories are Social life nouns (state, England, life, god, commons); Person nouns (people, lords, human, man, children) and Activity nouns (appeal, education, work, production, employment). The semantic categories, frequencies, and percentages of semantic sequence of Right 1 collocates are shown in the following Table 6.

Table 6

Semantic Categories, Frequencies, and Percentages of R1C

\begin{tabular}{lll}
\hline Semantic categories & NF & $\%$ \\
\hline Social life nouns & 365 & 27.32 \\
Person nouns & 171 & 12.8 \\
Activity nouns & 132 & 9.88 \\
\hline
\end{tabular}

Table 6 shows that the top three semantic categories in the Right 1 position often occupied by the words express social life, person and activities.

\section{Construction of Units of Meaning}

From the above analysis of the semantic categories of collocational framework in the Left 1, Middle, and Right 1 collocates, the semantic categories and their percentages are as follows:

Left 1: Existence verbs (37.78\%)/Activity verbs (19.79\%)/Mental verbs (11.99\%)

Middle: Activity nouns (28.33\%)/Essence nouns (28.04\%)/Quantity nouns (13.13\%)

Right 1: Social Life nouns (27.32\%)/Person nouns (12.8\%)/Topical (9.66\%) 
Hence based on the above percentage of semantic categories in each position, and we choose the top two percentages of each category, therefore, the most typical semantic sequences can be parsed as:

Existences/Activities + the + Activities/Essences + of + Social Lives/Persons

These sequences construct the typical semantic sequences of five-word string "L1C + the $+\mathrm{MidC}+$ of + R1C". These semantic sequences express either "exist the activities or essences of social life and person" or "act the activities or essences of social life and person".

\section{Conclusion}

This study investigates the lexical grammatical features of collocational framework and the construction of units of meaning based on collocational framework. It embodies Sinclair's lexical grammar model. The research results show that the collocational framework only consisting of two functional words can build up units of meaning in a huge amount of cases in meaningful context. The construction process initiated by collocation and ended with semantic patterns reflects the nature of units of meaning based on collocational framework, which consists of form, meaning and function in general English.

\section{References}

Altenberg, B. (1998). On the phraseology of spoken English: The evidence of recurrent word-combinations. In A.P. Cowie (Ed.), Phraseology. Theory, Analysis, and Applications (pp. 101-122). Oxford: Oxford University Press.

Biber, D., Conrad S., \& Cortes, V. (2004). If you look at...: Lexical bundles in university teaching and textbooks. Applied Linguistics, 25(3), 371-405.

Biber, D., \& Conrad, S. (1999). Lexical bundles in conversation and academic prose. In H. Hasselgard and S. Oksefjell (Eds.), Out of corpora (pp. 181-190). Amsterdam-Atlanta GA: Rodopi.

Biber, D., Conrad, S., Johansson, S., \& Leech, G. (1999). Longman grammar of spoken and written English. London: Pearson Education Limited.

Eeg-Olofsson, M., \& Altenberg, B. (1994). Discontinuous recurrent work combinations in the London-Lund Corpus. In U. Fries, G. Tottie, and P. Schneider (Eds.), Creating and using English language corpora: Papers from the Fourteenth International Conference on English Language Research on Computerized Corpora (pp. 63-77). Atlanta: Rodopi.

Halliday, M. A. K. (2009). Seminar: Language in science and the humanities. Hong Kong: The Hong Kong Polytechnic University.

Halliday, M., \& Matthiessen, C. (2004). An introduction to functional grammar (3rd ed.). London: Arnold.

Hunston, S., \& Francis, G. (2000). Pattern grammar: A corpus-driven approach to the lexical grammar of English. Amsterdam: John Benjamins.

Marco, M. J. L. (2000). Collocational frameworks in medical research papers: A genre-based study. English for Specific Purposes, $19(1), 63-86$.

Renouf, A. J., \& Sinclair, J. (1991). Collocational frameworks in English. In K. Ajimer and B. Altenberg (Eds.), English corpus linguistics. Studies in honour of Jan Svartvik (pp. 128-143). Harlow: Longman.

Sinclair, J. (1987). Collocation: A progress report. In R. Steel and T. Threadgold (Eds.), Language topics: Essays in honor of Michael Halliday (pp. 319-331). Philadelphia, PA: John Benjamins.

Sinclair, J. (1996). The search for units of meaning. Textus IX, 75-106.

Sinclair, J. (2004). The search for Units of meaning. In J. Sinclair and R. Carter (Eds.), Trust the text: Language, corpus and discourse (pp. 9-23). London: Routledge.

Sinclair, J. (2007). Collocation reviewed (Manuscript). Italy: Tuscan Word Centre.

Stubbs, M. (2002). Two quantitative methods of studying phraseology in English. International Journal of Corpus Linguistics, 7(2), 215-244.

Stubbs, M. (2007). An example of frequent English phraseology: Distribution, structures and functions. In R. Facchinetti (Ed.), Corpus linguistics 25 years on (pp. 89-105). Amsterdam: Rodopi. 